https://doi.org/10.48009/1_iis_2010_266-273

\title{
MEASURING JOURNAL QUALITY: PROPOSED CRITERIA AND THEIR APPLICATION TO IS JOURNALS
}

\author{
James J. Cappel, Central Michigan University, james.cappel@cmich.edu
}

\begin{abstract}
Assessing journal quality appears to be an issue of growing importance for AACSB accredited institutions. Beyond reviewing the quantity of faculty publications, the AACSB will reportedly give increased scrutiny to the quality of those publications. This article chronicles the experiences of a College of Business faculty development committee at a large public university in the Midwest to develop standard, objective criteria for evaluating journal quality. This article addresses many issues that surfaced in this effort and how they were resolved. This study also investigates how 125 Information Systems publications are evaluated based on use of these criteria. The proposed criteria and insights offered are designed to benefit other institutions that may be grappling with the thorny problem of how to assess journal quality in evaluating faculty research.
\end{abstract}

Keywords: Research Issues and Methodologies; IS Journal Quality; Case Study

\section{INTRODUCTION}

The Association to Advance Collegiate Schools of Business-International (AACSB) specifies that their accredited institutions are to set clear expectations for faculty "regarding the quality of intellectual contributions and how quality is assured (e.g., specific target journals or outlets, selectivity requirements, etc.)" [1, p. 23]. Additionally, a 2008 AACSB Research Task Force report included a recommendation to require "schools to demonstrate the impact of faculty intellectual contributions on targeted audiences" [2, p. 29]. These mandates place an increased focus on schools to provide greater evidence of the quality of faculty research publications in the accreditation process. For example, they entail additional reporting requirements such as detailing the number of faculty publications by specific journal. This process is likely to bring greater visibility to problems that may exist such as the preponderance of faculty publications being in lower quality journals or faculty repeatedly publishing in the same journals.
The author serves on a college Faculty Development Committee (FDC) whose role is to promote faculty teaching and research excellence. Early in the 20082009 academic year, the Dean met with our committee to urge action to promote faculty research in higher quality publications. According to the Dean, faculty members were not frequently targeting high quality journals in their research submissions and they tended to publish in the same journals over time. Thus, an opportunity existed to improve the quality of faculty research to advance the reputation of the college and to demonstrate greater evidence of research excellence to the AACSB. In a subsequent meeting, after extensive discussion of the administration's request, the FDC decided that evaluating journal quality was not a task they wanted to pursue and they directed their efforts toward other issues. The committee concluded that judging journal quality was difficult, controversial, and a matter that was best decided by the departments themselves. Thus, the committee took no action on this initiative.

At the start of the next academic year, a new Interim Dean met with the FDC to urge committee action on the journal quality issue. Since this Dean identified this matter as a high priority, the committee reconsidered its position and focused renewed attention on this issue. The discussion about how to promote and reward higher quality research quickly turned to the possible revision of the college's Research Credit Program. This program had been in existence for at least a dozen years without modification. This program granted a $\$ 500$ research credit to faculty who obtained a journal acceptance in a double-blind, peer-reviewed journal listed in Cabell's Directory. This remuneration went into the faculty member's account to be used for professional development purposes. If a publication was coauthored by more than one faculty member, the award was split between the authors. Over time, the actual magnitude of this award had dwindled with inflation. In addition, this program was arguably unfair in that it rewarded a publication in the highest level journals the same as publication in journals whose reputation is far less. Thus, a revised Research Credit Program could potentially remove this inequity and encourage faculty to target higher quality journals. 


\section{CRITERIA DEVELOPMENT}

In October 2009, the Committee began deliberation on revision of the college's Research Credit Program and the search for criteria to evaluate journal quality. The committee sought to identify clear, fair, objective standards to measure journal quality. The committee did not want to spend an inordinate amount of their time or the Dean's office time with evaluating the quality of publications on a case-by-case basis. They also did not want to have to hear appeals from faculty whose publications were denied by any standards that were developed.

An initial proposal focused on revising the Research Credit Program to create a three-tier structure. Under this plan, the standard research credit of $\$ 500$ would be maintained for qualifying publications listed in Cabell's Directory. A higher level award, referred to as an Enhanced Research Credit, of \$1,000 would be instituted for publication in a second-tier journal listed in the Journal Citation Reports (JCR) of the ISI Web of Knowledge [7]. This online resource, available at our university library's website, is based on a journal's impact factor, i.e., how frequently it is cited by other publications. The more frequently a journal is cited, the higher its impact factor. Journals with a sufficiently high impact factor as defined by $J C R$ are listed in this resource. Finally, the proposed plan would have created a top-level award of $\$ 1,500$ for publication in the very highest quality journals in a field. These were defined as a "handful" of publications that represented journals with the highest reputation. The committee was divided on their enthusiasm for this proposal. Some members wanted to move swiftly ahead on it, while others urged caution and further study. After some debate, the committee decided to proceed using a measured approach.

FDC members were asked to review the initial proposal with their departments to get faculty feedback and to assess its feasibility. This process resulted in the identification of some important problems with the higher-tier measures. A closer look at Journal Citation Reports revealed some significant concerns about its applicability and fairness across different fields of business. While some disciplines such as Economics, Finance, and Management had many publications represented in JCR $(209,48$, and 89 , respectively), other business fields such as Information Systems, Accounting, Marketing, and Business Communications were not even shown as separate category in JCR. For example, the number of IS publications appeared to be limited and they had to be located under the "Business" or
"Management" categories of JCR's Social Sciences Edition or in the JCR's Science Edition under one of several "Computer Science" sub-categories. This raised some doubts among faculty whether JCR grants proper recognition to all fields of business. In addition, some IS journals of considerable quality were not included in JCR such as Journal of the AIS, the Information Resources Management Journal, The Database for Advances in Information Systems, and the Journal of Computer Information Systems. This may have occurred since JCR has an application process. While the details of this process could not be located, new journals or ones that has not filed an application apparently may be excluded from JCR. Based on these concerns, several committee members argued that if $J C R$ is used as a measure of journal quality, it should be supplemented with other criteria.

While the idea of creating a third-tier award to provide even greater compensation was appealing to faculty, some committee members pointed out that the identification of a "handful" of top publications by each department would be problematic for several reasons. First, some of the college's departments are hybrid departments. For example, the Business Information Systems department includes Information Systems, Business Teacher Education, and Business Communications. For departments such as this, how many publications should be allocated to each area if the department were asked to select its "handful" of top journals? In addition, most departments have different areas of specialization. If the Accounting department for example were asked to identify its "handful" of top publications, what should be the distribution of these journals across the specializations of Auditing, Financial Accounting, Managerial Accounting, Taxation, Accounting Information Systems, and so on? Finally, would it be fair to mandate that all departments should have the same number of top-tier publications? Or, would this result in unfair quality differences in the lists of different departments? Since these questions were not easily answered and publication by faculty in the toptier publications was very infrequent given the teaching emphasis of our institution, the committee decided to abandon the "top-tier" concept and focus on a two-tier system.

Subsequent committee efforts concentrated on developing other criteria to supplement $J C R$ as a quality measure. The next criterion added was the use of journal acceptance rates in Cabell's Directory (online edition), specifically, the use of $20 \%$ as the maximum acceptance rate [6]. Although some committee members pointed out that this measure is not "perfect" in that these rates are self-reported by 
journals, it nevertheless has some advantages. First, this measure recognizes some quality journals such as the Journal of Computer Information Systems and the Information Resources Management Journal that were not included in JCR. The use of $20 \%$ as the maximum acceptance rate avoided some problems that would have otherwise been encountered with the use of other thresholds. Cabell's Directory allows journals to report either a specific acceptance rate or a range of rates. If the maximum acceptance rate was established at $15 \%$, this rate is in the middle of an 11 $20 \%$ acceptance range that a number of journals report; if the rate was set at $25 \%$, this rate would fall within the reported acceptance rates of other journals that are $21-30 \%$. The use of $20 \%$ resulted by far in the "cleanest" dividing line while producing a list of very respectable journals.

A third journal quality criterion added was the Association of Business Schools Academic Journal Quality Guide [3]. This guide is used more frequently by universities in Europe and it reportedly "is based on peer review, statistical information relating to citations, and editorial judgments from the detailed evaluations of many hundreds of publications over a long period" [3]. The $A B S$ guide lists a ranking for each journal, with 1 being the lowest and 4 the highest. In the final proposal, those journals listed in $A B S$ with a ranking of 2 or above were considered as higher quality publications.

Two additional issues had to be overcome in the development of this proposal. First, the Business Law (BLAW) faculty was strongly against the exclusive use of the first three criteria. They pointed out that virtually no business law publications were included in these sources and that their publications are relatively unique compared to other fields of business. For these reasons, the BLAW faculty proposed the use of a fourth criterion, the Washington and Lee University legal database which covers law reviews and journals [9].

Second, as committee discussions continued, there was an expansion of the criteria. For example, some members argued that given the teaching emphasis of our institution and a lack of resources to support toplevel research, the maximum acceptance rate in Cabell's Directory should be expanded from $20 \%$ to $30 \%$. Additionally, some members contended that any publication listed in $A B S$ should be included instead of only those with a ranking of 2 or higher. The expansion of these measures was passed at one point by the committee. However, the Dean later rejected these criteria stating that they were overly inclusive and that the college lacked sufficient funding to support them. Thus, the scope of the second and third criteria was scaled back in the final proposal. This proposal stated:

"For purposes of the College of Business Enhanced Research Credit program, a premium publication is defined as a journal that meets one of the following four criteria:

1. Any journal that is listed in the Journal Citation Reports of the ISI Web of Knowledge. This includes ALL the Social Science Journals \& ALL the Science Journals. (These can be accessed at: http://0-adminapps.isiknowledge.com.catalog.lib.cmich.edu/JC $\underline{\mathrm{R} / \mathrm{JCR} \text { ?SID=1ADj4cAbie\%40OoJAJ2fh }}$

2. Any journal that is listed in Cabell's Online Directory with an acceptance rate less than or equal to $20 \%$, i.e. the highest reported acceptance rate can be no higher than $20 \%$.

3. Any journal that is listed in the Association of Business Schools Academic Journal Quality Guide (the Keele University guide) with an ABS ranking (usually displayed in the fourth column of the table) of two or higher. These rankings can be accessed at http://www.the-abs.org.uk/?id=465.

4. Any publication listed in the Washington and Lee University law journal database with a combined impact factor greater than 0 . These can be accessed at http://lawlib.wlu.edu/LJ/index.aspx.."

Note that the term "premium publication" was used in the final proposal. This name resulted after considerable debate. Names proposed in earlier drafts included "higher level publication" and "respectable publication." These labels were found to be offensive to some faculty since they might imply that the college did not value publications in journals that did not meet the criteria for the higher level award. The committee wanted to avoid this perception and they ultimately decided that "premium publication" was a more fitting, neutral term.

\section{METHODOLOGY}

To assess the application of the criteria to information systems journals, a list of 125 IS journals was obtained from the "MIS Journal Rankings" page of the Association for Information Systems (AIS) website [4]. This list was compiled by AIS based on publications identified in nine previously published studies of journal quality. The AIS journal list was used for purposes of this study due to its availability 
and the likelihood that it would encompass most journals in the Information Systems field. Closer inspection of AIS journal list revealed that it did not contain at least 18 publications listed in Cabell's Directory; these publications included Issues in Information Systems, The Information Society, Enterprise Information Systems, and the Information Technology Journal. Nevertheless, the AIS list was considered reasonably inclusive for purposes of this analysis. Each publication on the AIS list was checked using the first three journal quality criteria; the fourth criterion was not considered since its focus is business law publications. The data collection was conducted in January and February of 2010. The results are described in the next section.

\section{RESULTS}

The complete findings for how each of the 125 IS journals are evaluated using the first three journal quality criteria is presented in Appendix 1. As indicated, there is considerable variation across the different measures in terms of which journals they do and do not include. As shown at the bottom of the last two columns of the table, whereas only about $18 \%$ of the 125 journals met all three criteria, most publications $(70 \%)$ met at least one of the three criteria, which is the key measure for a publication to qualify for the Enhanced Research Credit. Among individual criterion measures, the highest percentage of publications (54\%) met criterion 1, inclusion in Journal Citation Reports, followed by criterion 3 (inclusion in $A B S$ with a ranking of 2 or higher) at $46 \%$, and criterion 2 (inclusion in Cabell's Directory with an acceptance rate of $20 \%$ or less) which $29 \%$ of the journals met. Interestingly, 33 of the 125 journals met only a single criterion, and this included instances of publications meeting one of each of the three criteria but not the other two. For example, while the results suggest that criterion 2 (Cabell's Directory) is the most exclusive of the three measures, seven journals met this criterion but did not meet the other two. A total of 57 of the 125 publications were listed in Cabell's Directory but only 36 of these met the $20 \%$ or less maximum acceptance rate test. Finally, 66 journals were listed in $A B S$ but 8 of those journals did not meet the ranking test of 2 or above.

Based on the use of these three criteria, the departments of the college estimated that about $20 \%$ of faculty publications would likely qualify for the Enhanced Research Credit. This estimate was based on each department reviewing their publications for the past five years and assuming that similar publications would occur in the future. Of course if the incentive program motivated faculty to target higher quality journals as intended, this percentage would actually be expected to rise somewhat.

\section{CONCLUSIONS}

This effort to develop journal quality criteria and provide an incentive program to encourage higher quality research was a long, difficult, and controversial process. As indicated, the committee fought this task for more than a year before finally taking it on. The resulting proposal took five months to develop involving monthly meetings and extensive email discussions. One member even resigned from the committee during the discussion phase indicating that he was not comfortable with this initiative. A significant concern raised was that even though this issue was framed in terms of revising the college's Research Credit Program, some faculty were suspicious that it would ultimately affect department bylaws in terms of faculty research requirements for tenure and promotion. The Dean reassured the committee that this was not the case and he allowed the committee to insert language in the final proposal to clarify its intended purpose. The final proposal stated: "This award program is strictly and solely for the Research Credit Program established though the Office of the Dean... The Faculty Development Committee emphasizes that this program in no way is meant to compete with, supersede, interfere with, or serve as a model for CBA individual department bylaws. The determination of journal quality for promotion and tenure decisions is most comprehensively understood and determined at the department level, independent of any program established by the FDC." In the end, the committee voted unanimously to approve this proposal. At the time of this writing, this proposal is awaiting a final decision by a newly hired Dean who assumed his duties in July 2010.

The criteria presented in this article provide only one possible solution to the dilemma of how to evaluate journal quality. The criteria resulted from careful deliberation and they were ultimately accepted by faculty for the purpose of revising the college's Research Credit Program. The criteria are clear and objective, and they facilitate the efficient administration of this program. These criteria may be useful to faculty at other institutions in providing a starting point to develop or revise their own standards to evaluate journal quality. Any standards adopted by an institution should be developed only after careful input from key stakeholders and reflection on the focus and mission of the university. For example, it would appear to be unfair for a school to expect 
faculty to publish multiple articles in the very highest quality journals where an institution is teachingoriented, few resources such as graduate assistants are available, and faculty have a full teaching load with multiple course preparations. The journal quality measures proposed in this article were found to be acceptable at the author's institution that is primarily teaching-oriented, but the publishing expectations (and journal quality criteria) for a research-oriented institution would be considerably higher.

It should be stressed that other methods for evaluating journal quality also exist. For example, expert opinion is often used as a means to rate or rank journals [8]. For example, at its website, the Association for Information Systems publishes a "Senior Scholars' Basket of Journals" to identify the top journals in the Information Systems field. These publications are: the European Journal of Information Systems, Information Systems Journal, Information Systems Research, Journal of AIS, Journal of MIS, and MIS Quarterly [5]. Interestingly, to underscore just how difficult judging journal quality is, this source goes on to add that two journals, the Journal of Strategic Information Systems and the Journal of Information Technology, could be added to this list without sacrificing any journal quality [4]. Thus, it is unclear whether AIS's list of "top IS journals" includes six or eight publications and undoubtedly there would be many differences of opinion with this list across the wider IS community. Creating a journal rankings list based on expert opinion usually involves greater effort than the process used to develop the four criteria described in this paper, since journals must be evaluated one at a time and many differences of opinion must be resolved.

As the AACSB continues their demands on business schools to demonstrate evidence of journal quality in faculty publications, there is a growing need for researchers at other institutions to share their thoughts, experiences and any criteria they use to assess journal quality with the wider academic community. The case study presented here provides a detailed description of the types of challenges that can be expected in a college's journey to establish journal quality standards along with some possible ideas for responding to these issues. Regrettably, since the program described in this paper is a plan that has yet to be officially approved, no reports are yet available about how well this plan works in practice.
1. AAACSB International - The Association to Advance Collegiate Schools of Business. "Eligibility Procedures and Accreditation Standards for Business Accreditation." Revised July 1, 2009. Available at: http://www.aacsb.edu/accreditation/AAACS B-STANDARDS-2010.pdf, Accessed March 8, 2010.

2. AAACSB International - The Association to Advance Collegiate Schools of Business. "Final Report of the AACSB International Impact of Research Task Force." Available at http://www.aacsb.edu/resource_centers/rese arch/Final/Impact_of_Research_ReportFINAL.PDF, Accessed March 8, 2010.

3. Association of Business Schools. "Version 3 of the Academic Journal Quality Guide." Available at http://www.theabs.org.uk/?id=465, Accessed March 8, 2010.

4. "MIS Journal Rankings." Association for Information Systems website. Available at http://ais.affiniscape.com/displaycommon.cf $\mathrm{m}$ ?an $=1$ \&subarticlenbr $=432$. Accessed March 5, 2010.

5. "Senior Scholar's Basket of Journals." Association for Information Systems website. Available at http://home.aisnet.org/displaycommon.cfm? an=1\&subarticlenbr=346. Accessed March 5, 2010.

6. Cabell's Directory of Publishing Opportunities. Online Edition. Available at http://0-

www.cabells.com.catalog.lib.cmich.edu/me mberarea.aspx, Accessed March 8, 2010.

7. Journal Citation Reports of the ISI Web of Knowledge. Available at: http://0-adminapps.isiknowledge.com.catalog.lib.cmich.ed $\underline{\mathrm{u} / \mathrm{JCR} / \mathrm{JCR} \text { ?SID=1ADj4cAbie\%40OoJAJ2f }}$ h. Accessed March 8, 2010.

8. Lewis, B. (2008). "Judging the Journals." BizEd (November-December), 42-45.

9. Washington and Lee University School of Law. "Law Journals: Submissions and Rankings." Available at http://lawlib.wlu.edu/LJ/index.aspx, Accessed March 8, 2010.

\section{REFERENCES}


Appendix 1. Results

\begin{tabular}{|c|c|c|c|c|c|c|}
\hline $\begin{array}{c}\text { AIS } \\
\text { Rank } \\
\end{array}$ & Journal & $\begin{array}{l}\text { Crit. 1: } \\
\text { Listed } \\
\text { in } J C R ?\end{array}$ & $\begin{array}{l}\text { Crit. 2: } \\
\text { Listed in } \\
\text { Cabell's } \\
\text { Directory } \\
\text { with an } \\
\text { Acc Rate } \\
<=20 \%\end{array}$ & $\begin{array}{l}\frac{\text { Crit. 3: }}{\text { Listed }} \\
\text { in } A B S \\
\text { with a } \\
\text { rating } \\
>=2 ?\end{array}$ & $\begin{array}{c}\text { Journal } \\
\text { meets } \\
\text { all three } \\
\text { criteria }\end{array}$ & $\begin{array}{c}\text { Journal } \\
\text { meets } \\
\text { at least } \\
\text { one of the } \\
\text { three } \\
\text { criteria }\end{array}$ \\
\hline 1 & MIS Quarterly & YES & YES & YES & Yes & YES \\
\hline 2 & Information Systems Research & YES & No & No & No & YES \\
\hline 3 & Communications of the ACM & YES & No & YES & No & YES \\
\hline 4 & Management Science & YES & YES & YES & Yes & YES \\
\hline 5 & Journal of Mgmt. Info. Systems & YES & YES & YES & Yes & YES \\
\hline 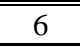 & Artificial Intelligence & YES & $\mathrm{No}$ & YES & No & YES \\
\hline 7 & Decision Sciences & YES & YES & YES & Yes & YES \\
\hline 8 & Harvard Business Review & YES & YES & YES & Yes & YES \\
\hline 9 & IEEE Transactions (various) & No & No & YES & No & YES \\
\hline 10 & AI Magazine & YES & No & No & No & YES \\
\hline 11 & European Journ. of Info. Systems & YES & YES & YES & Yes & YES \\
\hline 12 & Decision Support Systems & YES & No & YES & No & YES \\
\hline 13 & IEEE Software & YES & No & No & No & YES \\
\hline 14 & Information \& Management & YES & YES & YES & Yes & YES \\
\hline 15 & ACM Trans. on Database Systems & YES & $\mathrm{No}$ & YES & No & YES \\
\hline 16 & IEEE Trans. on Software Engin. & YES & No & YES & No & YES \\
\hline 17 & "ACM Transactions (various) & No & No & YES & No & YES \\
\hline 18 & Journal of Comp. and System Scis. & YES & No & YES & No & YES \\
\hline 19 & Sloan Management Review & YES & YES & YES & Yes & YES \\
\hline 20 & Communications of the AIS & $\mathrm{No}$ & No & YES & No & YES \\
\hline 21 & IEEE Trans. on Systs, Man, and Cyber. & YES & No & No & No & YES \\
\hline 22 & ACM Computing Surveys & YES & No & YES & No & YES \\
\hline 23 & $\begin{array}{l}\text { Journal on Computing } \\
\end{array}$ & No & No & No & No & No \\
\hline 24 & Academy of Mgmt. Journal & YES & YES & YES & Yes & YES \\
\hline 25 & International Journ. of Elect. Comm. & YES & No & No & No & YES \\
\hline 26 & Journal of the AIS & No & No & YES & No & YES \\
\hline 27 & IEEE Transactions on Computers & YES & No & YES & No & YES \\
\hline 28 & Information Systems Frontiers & YES & No & YES & No & YES \\
\hline 29 & Journal of Management Systems & YES & No & No & No & YES \\
\hline 30 & Organization Science & YES & No & YES & No & YES \\
\hline 31 & IEEE Computer & No & No & $\mathrm{No}$ & No & No \\
\hline 32 & Information Systems Journal & YES & YES & YES & Yes & YES \\
\hline 33 & Administrative Science Quarterly & YES & No & YES & No & YES \\
\hline 34 & Journal of Global Information Mgmt. & YES & YES & YES & Yes & YES \\
\hline 35 & $\begin{array}{l}\text { The DATABASE for Advs. in Info. Systs. } \\
\end{array}$ & No & No & No & No & No \\
\hline 36 & Journal of Database Management & YES & YES & YES & Yes & YES \\
\hline 37 & Information Systems & YES & No & No & No & YES \\
\hline 38 & MISQ Discovery & No & YES & No & No & YES \\
\hline 39 & Academy of Management Review & YES & No & YES & No & YES \\
\hline 40 & Journal of the ACM & No & No & No & No & No \\
\hline 41 & Computers and Operations Research & YES & No & YES & No & YES \\
\hline
\end{tabular}




\begin{tabular}{|c|c|c|c|c|c|c|}
\hline 42 & Human-Computer Interaction & YES & No & YES & No & YES \\
\hline 43 & "California Management Review & YES & YES & YES & Yes & YES \\
\hline 44 & Information Technology and People & No & YES & YES & No & YES \\
\hline 45 & "Journal of Strategic Info. Systems & YES & YES & YES & Yes & YES \\
\hline 46 & "Journal of Global Info. Tech. Mgmt. & No & YES & YES & No & YES \\
\hline 47 & ACM Transactions on Info. Systems & YES & No & YES & No & YES \\
\hline 48 & Informing Science & $\mathrm{No}$ & YES & No & No & YES \\
\hline 49 & Journal of Info. Management & No & $\mathrm{No}$ & $\mathrm{No \textrm {No }}$ & $\mathrm{No \textrm {No }}$ & No \\
\hline ב50 & Operations Research & YES & YES & YES & Yes & YES \\
\hline 51 & "Journal of Computer Info. Systems & $\mathrm{No}$ & YES & YES & No & YES \\
\hline 52 & Business Horizons & No & No & No & No & No \\
\hline 53 & IEEE Trans. on Knowl. and Data Engin. & YES & No & YES & No & YES \\
\hline 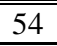 & Journal of Database Administration & No & No & No & No & No \\
\hline 55 & IBM Systems Journal & YES & No & No & No & YES \\
\hline 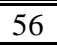 & Infosystems & No & No & No & No & No \\
\hline 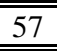 & " Journal of Info. Tech. Thy. and Applic. & No & No & No & No & No \\
\hline 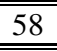 & Knowledge Based Systems & YES & No & No & No & YES \\
\hline 59 & Computer Decisions & No & No & No & No & No \\
\hline 60 & Information Technology and Mgmt. & No & No & No & No & No \\
\hline 61 & "WIRT (Wirtschaftsinformatik) & YES & No & No & No & YES \\
\hline 62 & Info. and Org. (frmrly Acct., Mgt, and IT) & No & No & YES & No & YES \\
\hline 63 & ACM Special Interest Group Publications & No & No & No & No & No \\
\hline 64 & Expert Systems with Applications & YES & YES & YES & Yes & YES \\
\hline 65 & Information Systems Management & YES & YES & YES & Yes & YES \\
\hline 66 & Interfaces (INFORMS) & YES & YES & YES & Yes & YES \\
\hline 67 & Omega & YES & No & YES & No & YES \\
\hline 68 & Interntl. Journ. of Human-Comp. Studies & YES & YES & YES & Yes & YES \\
\hline 69 & Database & $\mathrm{No}$ & $\mathrm{No}$ & YES & $\mathrm{No}$ & YES \\
\hline 70 & "Journal of Systems and Software & YYES & No & $\mathrm{No}$ & "No & YES \\
\hline 71 & Data Management & No & No & No & No & No \\
\hline 72 & Interntl. Journ. of Man-Machine Studies & No & No & No & No & No \\
\hline 73 & Journal of Info. Systems (Accounting) & No & No & YES & No & YES \\
\hline 74 & Journal of Info. Systems Management & No & No & No & No & No \\
\hline 75 & Journal of Information Technology & YES & YES & YES & Yes & YES \\
\hline 76 & Journal of Operations Research & No & No & No & No & No \\
\hline 77 & " Journal of Org. Comp. and Elect. Comm. & YES & YES & No & No & YES \\
\hline 78 & Info. Resources Management Journal & $\mathrm{No}$ & YES & $\mathrm{No}$ & No & YES \\
\hline 79 & "Journal of IT Cases and Application & No & No & No & No & No \\
\hline 80 & Journal of Info. Systems Education & No & No & No & No & No \\
\hline 81 & Journal of Systems Management & No & No & No & No & No \\
\hline 82 & Journal of the Amer. Soc. for Info. Sci. & No & No & No & No & No \\
\hline 83 & Org. Behavior and Human Dec. Procs. & YES & No & YES & No & YES \\
\hline 84 & Electronic Markets & No & YES & No & No & YES \\
\hline 85 & A Australian Journal of Info. Systems & No & YES & No & No & YES \\
\hline 86 & "Journal of Org. and End User Computing & No & YES & No & No & YES \\
\hline 87 & $\begin{array}{l}\text { Computer Supported Cooperative Work } \\
\end{array}$ & No & No & No & No & No \\
\hline 88 & Journal of Information Science & YES & No & YES & No & YES \\
\hline 89 & Datamation & $\mathrm{No}$ & No & $\mathrm{No}$ & No & No \\
\hline 90 & INFOR & YES & No & "No & No & YES \\
\hline 91 & "Interntl. Journal of Info. Management & YES & No & YES & No & YES \\
\hline 92 & Journal of Info. Tech. Management & No & No & No & No & No \\
\hline
\end{tabular}




\begin{tabular}{|c|c|c|c|c|c|c|}
\hline 93 & Behavior and Information Technology & YES & No & YES & No & YES \\
\hline 94 & Expert Systems Review & No & No & $\mathrm{No}$ & No & No \\
\hline 95 & "Journal of Educ. for Mgmt. Info. Systems & No & No & No & No & No \\
\hline 96 & Computer Journal & YES & No & YES & No & YES \\
\hline 97 & Info. Processing and Management & YES & No & YES & No & YES \\
\hline 98 & "Elect. Comm. Research and Application & YES & YES & No & No & YES \\
\hline 99 & International Journal of Tech. Mgmt. & YES & YES & YES & Yes & YES \\
\hline 100 & "Journal of Info. Systems (Education) & No & No & YES & No & YES \\
\hline 101 & Computers in Human Behavior & YES & No & No & No & YES \\
\hline 102 & European Journ. of Operations Res. & YES & YES & No & No & YES \\
\hline 103 & The Information Society & $\mathrm{No}$ & No & YES & No & YES \\
\hline 104 & Communication Research & YES & No & $\mathrm{No}$ & No & YES \\
\hline 105 & Information Research & YES & No & No & No & YES \\
\hline 106 & Journal of International Info. Mgmt. & No & No & No & No & No \\
\hline 107 & E-Service Journal & No & No & No & No & No \\
\hline 108 & Information and Software Technology & YES & No & No & No & YES \\
\hline 109 & Simulation & YYES & No & No & No & YES \\
\hline 110 & "Database Programming and Design & $\mathrm{No}$ & No & No & No & No \\
\hline 111 & AI Expert & No & No & No & No & No \\
\hline 112 & "Journ. of Microcomputer Systems Mmgt. & No & No & No & No & No \\
\hline 113 & "Scandinavian Journal of Info. Systems & No & No & No & No & No \\
\hline 114 & ACM SIG E-Com Exchanges & No & No & No & No & No \\
\hline 115 & "Journal of Engin. and Tech. Mgmt. & YES & YES & YES & Yes & YES \\
\hline 116 & " Journal of Software Maintenance & YES & No & No & No & YES \\
\hline 117 & IInterface: The Comp. Educ. Quarterly & YYES & YES & No & No & YES \\
\hline 118 & "Journal of Info. Technology Education & No & YES & No & No & YES \\
\hline 119 & Computers and Automation & No & No & No & No & $\mathrm{No}$ \\
\hline 120 & Interntl. Journal of IT Mgmt. Systems & No & No & No & No & No \\
\hline 121 & IBSCUG Quarterly & No & No & No & No & No \\
\hline 122 & Information & "No & No & $\mathrm{No}$ & No & "No \\
\hline 123 & "Journal of Management & YES & No & YES & No & YES \\
\hline 124 & Quality Progress & $\mathrm{No}$ & No & No & No & No \\
\hline \multirow[t]{5}{*}{125} & PC World & $\mathrm{No}$ & No & $\mathrm{No}$ & $\mathrm{No}$ & $\mathrm{No}$ \\
\hline & Number of Yes's & 68 & 36 & 58 & 22 & 88 \\
\hline & Number of No's & 57 & 89 & 67 & 103 & 37 \\
\hline & Total Journals & 125 & 125 & 125 & 125 & 125 \\
\hline & Percentage of Yes's & $54.4 \%$ & $28.8 \%$ & $46.4 \%$ & $17.6 \%$ & $\overline{70.4 \%}$ \\
\hline
\end{tabular}

